\title{
Condições de saúde bucal em pessoas de 60 anos ou mais no Município de São Paulo (Brasil)
}

\author{
Oral health condition of people of 60 years of age or above in S. Paulo city, \\ Brazil
}

\section{Antonio Galvão Fortuna Rosa*, Roberto Augusto Castellanos Fernandez*, Vitor Gomes Pinto**, Luiz Roberto Ramos}

\begin{abstract}
ROSA, A.G.F. et al. Condições de saúde bucal em pessoas de 60 anos ou mais no Município de Såo Paulo (Brasil). Rev. Saúde públ., S. Paulo, 26: 155-60, 1992. As condições de saúde bucal no grupo populacional com 60 anos ou mais é estudada, na cidade de Sảo Paulo em 1989. Com base em dados referentes à cárie dental, doenças periodontais, necessidade e uso de prótese e prevalência de alterações em tecidos duros e moles, conclui-se que este grupo apresenta um nível muito precário de saúde bucal. Recomenda-se a definição de política e de programas odontológicos especificos para a terceira idade.
\end{abstract}

Descritores: Saúde bucal. Levantamentos de saúde bucal.

\section{Introdução}

A saúde bucal, componente essencial para a higidez do individuo, tem sido relegada ao esquecimento, no caso brasileiro, quando se discutem as condições de saúde da população idosa (terceira idade). A perda total de dentes (edentulismo) é aceita pela sociedade, pelos odontólogos e pelas pessoas adultas especificamente, como algo normal e natural com o avanço da idade, o que é falso. Os serviços públicos possuem limitada capacidade de atendimento para crianças e adolescentes e no que se refere a adultos limitam-se a fazer exodontias.

Com o declínio acentuado das taxas de mortalidade, o grupo da terceira idade - constituído por pessoas de 60 anos e mais - passou a representar uma parcela cada vez mais significativa da população, trazendo para paises em desenvolvimento, como o Brasil, uma realidade até há pouco tempo só reconhecida no mundo industrializado $9,11,15$. Estima-se que em 1990, $7 \%$ da população brasileira possuía 60 anos ou mais, devendo esse grupo representar $8 \%$ da população no ano $2000^{6}$.

Pesquisas epidemiológicas realizadas em

* Departamento de Prática de Saúde Pública da Faculdade de Saúde Pública da Universidade de São Paulo - São Paulo, Brasil

* Instituto de Pesquisa Econômica Aplicada (IPEA)- Brasilia, DF - Brasil

*** Setor de Geriatria e Gerontologia da Escola Paulista de Medicina - São Paulo, SP - Brasil

Separatas/Reprints: A.G.F. Rosa - Av. Dr. Amaldo, 715 01246-904 - São Paulo, SP - Brasil

Publicaçāo financiada pela FAPESP. Processo Saúde Coletiva 91/4994-0 outros países revelaram níveis precários de saúde bucal nesse grupo etário, mesmo em áreas industrializadas como na Inglaterra, Nova Zelândia, Dinamarca, Israel e Estados Unidos 2,3 5,7,12.

Os resultados do "Levantamento Epidemiológico em Saúde Bucal", realizado em 1986 no Brasil (zona urbana) ${ }^{13}$ mostraram condiçōes bastante críticas no grupo etátio de 50 a 59 anos de idade: 27 dentes atacados pela cárie por pessoa, com $86 \%$ dos dentes já extraídos e $3 \%$ com extração indicada. Do ponto de vista periodontal, pouco mais de $1 \%$ foi considerado sadio, ao passo que $50 \%$ eram edêntulos.

Considerando que nas últimas décadas a saúde bucal não tem sido valorizada pelas pessoas em geral e que a prevenção em odontologia no Brasil só passou a despertar interesse a partir do final da década de 70 , supõe-se que o grupo populacional de terceira idade deve apresentar baixos níveis de saúde bucal.

O presente estudo foi realizado em uma amostra geriátrica na cidade de São Paulo e integrado a uma pesquisa internacional promovida pela Federação Dentária Internacional (FDI) ${ }^{*^{4}}$. Trata-se de um estudo descritivo, cujo objetivo principal é fornecer um padrão referencial do estado de saúde bucal da populaçãó de 60 anos ou mais, porque não existem no Brasil dados de prevalência dos principais problemas de odontologia nesse grupo.

A FDI, atuou no Congresso Odontólogico Mundial de Buenos Aires, estruturou o Grupo de Trabalho 5 para estudar as "necessidades de saúde bucal dos idosos". O Grupo, composto por membros de diversos países entre os quais um brasileiro (Dr. Vitor G. Pinto), encerrou seus trabalhos em 1990 na reunião de Cingapura, devendo ter apresentado seu informe final em Milão, outubro/91. 


\section{Material e Método}

\section{Amostra}

O estudo foi realizado em dois grupos, ambos com idosos de 60 anos ou mais. O primeiro, utilizando uma subamostra de um estudo de Ra$\operatorname{mos}^{15}$

A amostra foi obtida com base em três grupos funcionais estratificados por nível de renda, no que diz respeito aos indivíduos residentes no seu domicílio, utilizando os seguintes critérios: localização geográfica, rede de esgotos instaladas e presença na área de pessoas com mais de 60 anos.

Foram selecionadas três regiōes com as seguintes características:

a) uma região central - bairro Aclimação, com alta renda per capita (US\$ 1,409 a 526), com boa disponibilidade de esgotos $(97,2 \%$ a $87,8 \%$ ) e alta proporção de pessoas com 60 anos ou mais $(8,91 \%$ a $6,62 \%)$;

b) Uma área intermediária - Vila Guilherme, com renda média de (US\$ 1,063 a 410), regular disponibilidade de rede de esgotos $(92,1 \%$ a $62,3 \%)$ e proporção mediana de pessoas com 60 anos e mais $(8,06 \%$ a $4,54 \%)$;

c) Uma área periférica - Vila Brasilândia, com baixa renda (US $\$ 457$ - 296), limitada disponibilidade de rede de esgotos $(78,0 \%$ a $19,7 \%$ ) e baixa proporção de pessoas com 60 anos e mais.

Para obtenção dessa amostra foi utilizado um tipo de metodologia que tornou-se conhecida como Plano Antáttica (1966) e que foi adotado pelo Brasil para a Pesquisa Nacional por Amostragem de Domicílios (1981) e que consiste em subdividir a área de estudo em pequenos agrupamentos com um tamanho padrão. Cada domicílio no agrupamento selecionado foi pesquisado para obter informação sobre moradia de pessoas com 60 anos e mais e o sexo a que pertenciam. Depois uma amostra randômica foi obtida usando uma proporção fixa de $30 \%$.

O segundo grupo foi constituído por pessoas idosas internadas em duas instituições: Irmandade da Santa Casa de Misericótdia de São Paulo, Departamento de Geriatria "Dom Pedro II" (Unidade de Prestaçāo de Serviços) e Lar dos Velhinhos "Ondina Lobo", que apresentavam problemas físicos debilitantes, crônicos, médicos e ou emocionais, fazendo com que fossem incapazes de manter independência funcional sem uma assistência continuada. As duas instituições acima foram as únicas no Município de São Paulo que permitiram que os internados fossem examinados, tratando-se, portanto, da população disponível para o estudo.

$\mathrm{Na}$ Tabela 1, podemos observar o número de idosos examinados segundo o local do exame.

Tabela 1 - Número de idosos examinados e média de idade, segundo o local do exame e sexo. Sáo Paulo, 1989.

\begin{tabular}{|c|c|c|c|c|}
\hline \multirow{2}{*}{$\begin{array}{l}\text { Local de } \\
\text { Exame }\end{array}$} & \multicolumn{2}{|c|}{ Sexo } & \multirow[t]{2}{*}{ Total } & \multirow{2}{*}{$\begin{array}{c}\text { Média de } \\
\text { Idade }\end{array}$} \\
\hline & Masculino & Feminino & & \\
\hline Domicilio & 32 & 52 & 84 & 70 \\
\hline Instituicāo & 77 & 75 & 152 & 77 \\
\hline Total & 109 & 127 & 236 & 73,5 \\
\hline
\end{tabular}

\section{Indices Epidemiológicos}

Para medir a ocorrência da cárie dental foi empregado o indice CPO-D, descrito pela primeira vez por Klein e Palmer (1937) ${ }^{10}$, que nos dá o número de dentes permanentes cariados, perdidos (extraídos) e obturados em um indivíduo. Os critérios de diagnósticos foram os utilizados pela Faculdade de Saúde Pública, Disciplina de Odontologia Sanitária ${ }^{16}$.

$O$ índice utilizado para avaliar as necessidades de tratamento periodontal - CPITN ${ }^{1}$ - fornece não só o número de pessoas a tratar, como também o tipo de tratamento necessário. Este índice considera o arco dental dividido em seis partes, cada uma dela constituindo um sextante a saber:

1) dentes posteriores superiores lado direito

2) dentes anteriores superiores

3) dentes posteriores superiores lado esquerdo

4) dentes posteriores inferiores lado esquerdo

5) dentes anteriores inferiores

6) dentes posteriores inferiores lado direito

Em relação às necessidades de prótese total, o exame concentrou-se na constatação da presença ou ausência de dentaduras, nos arcos superiot, inferior ou em ambas as arcadas.

Os individuos que apresentaram falhas dentais foram registrados como necessitando prótese parcial, desde que os dentes suporte estivessem em condições para apoio da prótese.

A avaliação das condições periodontais para determinar a profundidade da bolsa, a detecção do cálculo e a resposta ao sangramento, foi feita com a sonda periodontal da Organização Mundial de Saúde (OMS) 1 .

\section{Fichas de levantamento}

Foram utilizadas as fichas de levantamento (Anexo 1) preconizadas pela $\mathrm{OMS}^{14}$ com ficha 
complementar referente a dados sobre prótese e estruturas da boca.

O cabeçalho é autocompreensível, contendo dados do indivíduo, local e data do exame.

Embora na ficha padronizada pela OMS, para pesquisas epidemiológicas sobre saúde bucal, constem campos para avaliação da má oclusão e fluotose, estes não foram utilizados no presente estudo porque não são pertinentes à população examinada. O estado periodontal foi registrado no campo CPITN e o ataque de cárie nos campos: estado dos dentes e sumário do CPO.

O complemento da ficha contém espaços para registros referentes à avaliação clínica dos tecidos moles, lesões relativias ao uso de prótese, necessidades e uso de próteses, total ou parcial.

\section{Exame clínico}

Os idosos foram examinados em cadeiras comuns, cadeira de rodas, camas (sentados ou deitados) dependendo do local de exame e do estado físico do indivíduo, sob luz artificial, com Burton's Lamp, lutilizando sondas exploradoras $n^{2} 5$; espelhos bucais com aumento; sondas periodontais da OMS; pinças $\mathrm{n}^{2} 17$.

$O$ instrumiantal foi esterilizado em autoclaves e transpoittado em cubetas.

Para os exämes domiciliares foram encaminhadas anteriormente cartas explicando o motivo do estudo e solicitando colaboraçāo para a realização dos exames.

Nas instituiçōes foram examinadas todos os internados presentes nos dias dos exames e colocados pelos responsáveis à diposição dos examinadores.

\section{Análise dos Resultados}

$\mathrm{Na}$ Tabela 2 podemos observar a prevalência da cárie dental nos dois grupos.

Comprovou-se com nitidez, os altos índices de cáries na terceira idade, o que já era esperado tendo em vista que desde a idade escolar os índices da cárie do Brasil estāo entre os maiores do mundo. Segundo o Levantemento Nacional de Saúde Bucal do Brasil ${ }^{13}$, no grupo etário 50-
59 anos, O CPO encontrado foi 27,2 com $86 \%$ de participação dos dentes extraídos. No presente estudo o CPO foi 29,03 para os examinados no domicílio com participaçāo de 93,5\% dos dentes extraídos e CPO 30,97 para os examinados nas instituições com participação de $96,1 \%$ dos dentes extraídos, mostrando que o problema continua aumentando à medida que a idade avança.

As necessidades de tratamento para os dois grupos (C+ED) são desprezíveis não chegando a 2 dentes em média.

Levantamentos similares realizados na mesma época na Nova Zelândia indicaram um CPO de 28,9 com participaçāo de $\mathbf{8 7 \%}$ dos dentes extraidos, enquanto no Reino Unido o CPO encontrado foi 26,4 com participação dos dentes extraídos na proporção de $96 \%^{5}$. Por outro lado, países que enfatizam açōes de saúde bucal, orientadas para a prevenção em adultos, mostram um quadro odontológico um pouco melhor na terceira idade. Os Estados Unidos, por exemplo, apresentam um CPO-D de 18,37 com participação de $59 \%$ dos dentes extraídos, no mesmo grupo populacional ${ }^{8}$.

$\mathrm{Na}$ Tabela 3 podemos observar os dados relativos ao uso e necessidades de prótese total.

Tabela 3 - Percentagem de edêntulos segundo o local de exames e situação. São Paulo, 1989.

\begin{tabular}{lcc}
\hline \multicolumn{1}{c}{ Situaçáo } & $\begin{array}{c}\text { Domicilio } \\
(\mathrm{N}=55)\end{array}$ & $\begin{array}{c}\text { Instituiçāo } \\
(\mathrm{N}=127)\end{array}$ \\
\hline $\begin{array}{l}\text { Usando apenas } \\
\text { prótese total superior }\end{array}$ & $13 \%$ & $15 \%$ \\
$\begin{array}{l}\text { Usando prótese total } \\
\text { superior + inferior }\end{array}$ & $76 \%$ & $30 \%$ \\
$\begin{array}{l}\text { Necessitando prótese } \\
\text { total superior }+ \text { inferior }\end{array}$ & $11 \%$ & $55 \%$ \\
\hline Total & $100 \%$ & $100 \%$ \\
\hline
\end{tabular}

Dos indivíduos examinados no domicílio, $65 \%$ eram edêntulos e destes $76 \%$ usavam prótese total superior e inferior, estando portanto com a mastigação reabilitada. O restante usava apenas prótese superior (13\%) ou necessitava

Tabela 2 - Número médio e percentual de dentes cariados, obturados, extraídos e com extraçāo indicada no Grupo etário 60 anos ou mais, segundo o local de exame, 1989.

\begin{tabular}{|c|c|c|c|c|c|c|c|c|c|c|}
\hline \multirow{2}{*}{$\begin{array}{l}\text { Local do } \\
\text { Exame }\end{array}$} & \multicolumn{2}{|c|}{ Cariados } & \multicolumn{2}{|c|}{ Obturados } & \multicolumn{2}{|c|}{ Extraidos } & \multicolumn{2}{|c|}{ Ext. Indic } & \multicolumn{2}{|c|}{ Total } \\
\hline & $\overline{\bar{c}}$ & $\%$ & $\overline{0}$ & $\%$ & $\overline{\bar{E}}$ & $\%$ & $\overline{\overline{E l}}$ & $\%$ & $\overline{\overline{\mathrm{CPO}}}$ & $\%$ \\
\hline Domicilio & 0,65 & 2,2 & 0,76 & 2,6 & 27,14 & 93,5 & 0,48 & 1,7 & 29,03 & 100, \\
\hline Instituicăo & 0,29 & 0,9 & 0,20 & 0,7 & 29,76 & 96,1 & 0,72 & 2,3 & 30,97 & 100 \\
\hline
\end{tabular}


prótese total superior + inferior (11\%). Em relaçāo aos examinados nas instituições, somente $30 \%$ usava prótese total superior e inferior e o restante apresentava o processo mastigatório deficiente. E provável que a diferença de pessoas desdentadas usando prótese total entre os dois grupos, deve-se ao fato das pessoas instituicionalizadas serem de baixa renda.

Em relação a outras necessidades protéticas, entre os examinados no domicilio $18 \%$ necessitavam de próteses parciais superiores ou inferiores, enquanto nas instituiçōes somente 7\% apresentavam esse tipo de necessidade.

A comparação dos resultados obtidos no presente estudo com os obtidos na Finlândia e Reino Unido (população de 60 anos ou mais) cujas necessidades de prótese total foram de $20 \%$ e $44 \%$ respectivamente ${ }^{5}$, incluindo as próteses que necessitavam substituição, indicam, como no Brasil ${ }^{13}$, o contínuo crescimento do CPO. A participação cada vez maior dos dentes extraídos, aliados à falta de assistência odontológica por carência de recursos próprios ou falhas no atendimento social, leva aos péssimos níveis de saúde bucal observados na terceira idade.

Em relação às necessidades de tratamento periodontal, os resultados podem ser vistos na Tabela 4.

Tabela 4 - Percentagem de sextantes segundo necessidade de tratamento periodontal e local de exame. São Paulo, 1989.

\begin{tabular}{|c|c|c|}
\hline \multirow{2}{*}{$\begin{array}{l}\text { Necessidades } \\
\text { de Tratamento }\end{array}$} & \multicolumn{2}{|c|}{ Número de Sextantes } \\
\hline & $\begin{array}{l}\text { Domicilio } \\
(N=92)\end{array}$ & $\begin{array}{l}\text { Instituição } \\
(N=88)\end{array}$ \\
\hline $\begin{array}{c}\text { Nenhum Tratamento } \\
(0)\end{array}$ & $1 \%$ & $9 \%$ \\
\hline $\begin{array}{l}\text { Higiene Oral } \\
\text { (I) }\end{array}$ & $4 \%$ & $1 \%$ \\
\hline $\begin{array}{c}\text { Higiene + Profilaxia } \\
\text { (II) }\end{array}$ & $45 \%$ & $23 \%$ \\
\hline $\begin{array}{c}\text { Higiene Oral + Profilaxia } \\
+ \text { Raspagem radicular } \\
\text { (III) }\end{array}$ & $27 \%$ & $33 \%$ \\
\hline $\begin{array}{l}\text { Higiene Oral + Profilaxia } \\
+ \text { Raspagem radicular + } \\
\text { Cirurgia } \\
\begin{array}{l}\text { (IV } \\
\end{array}\end{array}$ & $23 \%$ & $34 \%$ \\
\hline Total & $100 \%$ & $100 \%$ \\
\hline
\end{tabular}

As condições periondontais encontradas em ambos os grupos são severas. Nos domicílios $50 \%$ dos sextantes examinados necessitavam de tratamento complexo (tipos III e IV).

Já nas pessoas examinadas nas instituições, considerando as mesmas condições, este percentual eleva-se a $67 \%$. As más condiçōes periodontais encontradas irāo inevitavelmente determinar agravos na saúde bucal, incrementando o edentulismo. Se essas pessoas não tiveram recursos ou a assistência odontológica social não for capaz de limitar os danos quanto à cárie, pela lógica também não haverá o controle da doença periodontal, caminhando inexoravelmente para a perda total dos dentes. Nos Estados Unidos $22 \%$ dos idosos necessitavam tratamento mais complexo e na Nova Zelândia $41 \%^{5}$.

A Tabela 5 apresenta as lesões provocadas pelo uso de prótese total.

Tabela 5 - Percentagem de pessoas usando prótese total superior ou superior + inferior segundo a ocorrência de lesōes provocadas pelo uso da protése $\theta$ local de exame. São Paulo, 1989.

\begin{tabular}{lrr}
\hline $\begin{array}{c}\text { Ocorrência } \\
\text { de Lesōes }\end{array}$ & $\begin{array}{c}\text { Domicilio } \\
(N=50)\end{array}$ & $\begin{array}{r}\text { Instituição } \\
(\mathrm{N}=57)\end{array}$ \\
\hline Estomatite protética & $22 \%$ & $30 \%$ \\
Hiperplagia ou épulis & $8 \%$ & $16 \%$ \\
Outras lesões & $8 \%$ & $7 \%$ \\
Sem lesões & $62 \%$ & $47 \%$ \\
\hline Total & $100 \%$ & $100 \%$ \\
\hline
\end{tabular}

Foram examinados todos os individuos que portavam prótese total: no arco superior ou inferior e em ambos os arcos. $\mathrm{Na}$ Tabela 5 podemos observar que a qualidade das próteses deixa muito a desejar, pois, nos exames domiciliares $38 \%$ dos portadores de prótese total apresentavam lesões relativas à prótese, enquanto nos internados em instituições essa proporção atingia a 53\%. A lesão mais prevalente nos dois grupos foi a estomatite protética, com as hiperplasias ou épulis ocupando o segundo plano.

Tais fatos fazem supor inexistência de acompanhamento profissional após a colocação de prótese total.

Não foram observadas lesões com ulceração em nenhum portador de prótese total. As lesões observadas nos tecidos moles foram em pequeno número sendo as mais comuns: hemangioma e língua varicosa. Não foi observada clinicamente nenhuma lesão que indicasse a neccessidade de raspagem esfoliativa.

\section{Comentários Finais}

O estudo efetuado na cidade de São Paulo, onde o acesso aos serviços sociais figura, teoricamente, entre os mais favoráveis de todo o 
país, mostra que a população de terceira idade apresenta condições muito precárias de saúde bucal.

Aos 60 anos ou mais, a cárie dental atacou aproximadamente 30 dentes em ambos grupos $(\mathrm{CPO}=29,03$ e $\mathrm{CPO}=30,97)$. Dito de outra forma, em média cada pessoa possui apenas dois dentes sadios.

A participação dos dentes extraídos varia de 27 a 29 dentes evidenciando que o tratamento odontológico conservador falhou ou não existiu.

$O$ percentual de edêntulos, $65 \%$ no domicílio e $84 \%$ nas instituiçōes, indica que mais da metade e cerca de $3 / 4$ dos individuos, respectivamente, perderam todos os dentes, e apenas $76 \%$ no domicilio e $30 \%$ nas instituições usavam prótese total superior e inferior.

O elevado percentual de lesōes ligadas ao uso de próteses totais deixa clara a falta de assistência odontológica posterior à sua colocação.

Não é melhor a situação no que se refere às doenças periodontais: as bolsas periodontais predominaram em relação aos demais danos, exigindo tratamento mais complexo e portanto mais dispendioso, para metade dos examinados no domicilio e dois terços dos examinados nas instituições. Convém salientar que esse tipo de tratamento usualmente só é disponivel em clínicas particulares e conseqüentemente não está ao alcance da maioria das pessoas. De uma maneira geral, os maiores problemas estão presentes nas pessoas economicamente menos favorecidas (internados nas instituições beneficentes).

Na prática, os problemas de saúde bucal na terceira idade são relegados ao descaso no Brasil, transformando-se em fator de aceleração dos problemas naturais da velhice, tornando-a mais incômoda do que deveria ser.

Más condições de mastigação, lesões ligadas à prótese e ou doenças periodontais consituem agravos severos que precisam ser enfrentados, em primeiro lugar através de políticas nacionais, estaduais e municipais de saúde com ênfase na prevençāo, reduzindo os niveis de doença para que as necessidades de tratamento não sufoquem a capacidade de atendimento.

Levando em conta o ativo processo de descentralização que hoje caracteriza o Sistema de Saúde do país, sugere-se que açōes específicas de saúde bucal para a terceira idade devem ser inseridas o quanto antes nos programas de saúde municipalizados.

Os resultados aqui obtidos indicam a necessidade de novos e detalhados estudos em todo o pais, incluindo a população de 60 anos e mais como um componente habitual dos levantamen- tos epidemiológicos que ora em diante vierem a realizar-se.

Uma maior e melhor consciência profissional acerca dos problemas típicos da terceira idade precisa, com urgência, ser desenvolvida entre os cirurgiões dentistas brasileiros. $O$ combate à síndrome das extraçōes em massa e o estímulo à manutenção de condiçōes odontológicas funcionais na velhice devem constituir-se em pontos essenciais de cada programa de saúde bucal para que possamos superar, pouco a pouco, o crítico momento atual.

\section{Agradecimentos}

- A Santa Casa de Misericórdia de São Paulo e ao Lar dos Velhinhos "Ondina Lobo", por terem permitido a realização dos exames em seus internados.

- Ao Prof. Doutor Pedro Manuel Leal Germano, Professor Associado do HSP da FSP/USP, pela elaboração do programa de gerenciamento de dados.

- À Profa. Dra. Sabina Léa D. Gotlieb, Professora Associada do HEP da FSP/USP, pela revisão das tabelas.

ROSA, A.G.F et al. [Oral health conditions of people of 60 years of age or above in S. Paulo city, Brazil]. Rev. Saúde públ., 26:155-60, 1992. The oral health status of people aged 60 years or over in S. Paulo in 1989 is discussed. According to data relating to dental caries, periodontal diseases, need and use of prothesis and prevalence of hard and soft oral tissue pathologies, this study concludes that elder people present a very bad oral health status. The definition of a policy and dental care programs addressed to the aged are recommended.

Keywords: Oral health. Dental health surveys.

\section{Referências Bibliográficas}

1. AINAMO, J. et al. Development of the World Health Organization (WHO) Community Periodontal Index of Treatment Needs (CPITN). Int. dent. J., 32: 281-91, 1982.

2. BULMAN, J.S. et al. A survey of the dental health and attitudes towards dentistry two communities. Brit. dent. J., 124: 549-54, 1968.

3. BURGESS, W.C. \& BECK, D.J. Survey of denture wearers in New Zealand, 1968. N.Z. dent. J., 65: 223-32, 1968.

4. FEDERAÇĀO DENTARIA INTERNACIONAL (FDI). Working Group 5. Oral Needs of the Elderly. Comission on Oral Health, Research and Epidemiology. Amsterdam, 1987. [Mimeografado]. 
5. FEDERAÇÃo DENTÁRIA INTERNACIONAL (FDI). Working Group 5. Oral Needs of the Elderly. Comission on Oral Health, Research and Epidemiology. Relatório preliminar. Cingapura, 1990. [Mimeografado].

6. FUNDAÇĀo IBGE. Anudrio Estatistico do Brasil: 1987. Rio de Janeiro, 1988.

7. GRABOWSKY, M. \& BERTRAN, V. Oral health status and need of dental treatment in the elderly Danish population. Community dent. Oral Epidem, 3; 108-14, 1975.

8. JOHNSON, E.S. et al. Selected dental finding in adults by age, race and sex. United States, 1960-62. Vital Hlth Statist. Ser. 11, (7), 1965.

9. KALACHE, $K$ et al $O$ envelhecimento da populaçăo mundial: um desafio novo. Rev. Saúde públ., $S$. Paulo, 21: 200-10, 1987.

10. KLEIN, H. \& PALMER, C.E. Dental caries in American indian children. Publ. Hlth Bull., (239): 1-53, 1937.

11. LEAKE, J.L. et al. Results of the socio-dental survey of people aged $\mathbf{5 0}$ and older living in East York, Ontario. Canad J. publ. Hlth, 81: 120-4, 1990.

12. MANN, J. et al. Dental status and dental needs of an elderly population in Israel. Community dent. Oral Epidem., 13: 156-8, 1985.
13. MINISTÉRJO DA SAÚDE. Levantamento epidemiológico em sauide bucal, zona urbana 1986. Brasilia, Divisão Nacional de Saúde Bucal, 1988.

14. ORGANIZAÇĀO MUNDIAL DE SAÚDE. Levantamento epidemiológico búsico de saúde bucal. $3^{\mathrm{L}}$ ed. St̃o Paulo, Ed. Santos, 1991.

15. RAMOS L.R. et al Avaliaçăo das condições de vida e sauide de idosos residentes em zona urbana São Paulo, Brasil. [Projeto multicêntrico da Organizaçăo Panamericana da Saúde, com colaboração do Ministério da Saúde do Brasil - Mimeografado].

16. UNIVERSIDADE DE SÃo PAULO. Faculdade de Saúde Publica. Disciplina de Odontologia Sanitária. Critérios para exames e regras para o registro dos indices CPO e CPOS. São Paulo, 1967. [Mimeografado]. 